\title{
Efeito de Kasugamicina e Oxicloreto de Cobre no Controle da Mancha-Aquosa do Meloeiro
}

\author{
Rui Sales Júnior ${ }^{1 *}$, Idjane S. Oliveira ${ }^{2}$, Rosa L. R. Mariano ${ }^{2}$, George F. da Silva ${ }^{1 * *}$ \& Glauber H. S. Nunes ${ }^{1}$ \\ ${ }^{1}$ Departamento de Fitossanidade, Escola Superior de Agricultura de Mossoró, Cx. Postal 137, CEP 59625-900, Mossoró, \\ RN, e-mail: jrrui@ hotmail.com; ${ }^{2}$ Universidade Federal Rural de Pernambuco, Av. D. Manoel de Medeiros, s/n, \\ Dois Irmãos, CEP 52171-900, Recife-PE
}

(Aceito para publicação em 07/04/2005)

Autor para correspondência: Rui Sales Júnior

SALES JÚNIOR, R., OLIVEIRA, I.S., MARIANO, R.L.R., SILVA, G.F. \& NUNES, G.H.S. Efeito de kasugamicina e oxicloreto de cobre no controle da mancha aquosa do meloeiro. Fitopatologia Brasileira 30:295-298. 2005.

RESUMO

A mancha-aquosa, causada por Acidovorax avenae subsp. citrulli, é a mais importante doença bacteriana do meloeiro (Cucumis melo) no Nordeste. Objetivando buscar alternativas para seu controle, diferentes doses de kasugamicina (100, 200, 300, 500 e $700 \mathrm{ppm})$, oxicloreto de cobre $(500 \mathrm{ppm})$ e mistura dos dois produtos $(200+500 \mathrm{ppm})$ foram avaliadas quanto à inibição do patógeno, in vitro. Em seguida, dois ensaios de campo foram realizados no Rio Grande do Norte (RN) e Ceará (CE), registrando-se inicialmente as incidências médias da doença em plantas. Os tratamentos: 1 a 4 - kasugamicina 40, 50, 60 e 70 ppm; 5 - kasugamicina + oxicloreto de cobre $40+1250$ ppm; 6 - oxicloreto de cobre 1250 ppm; 7 - sal de oxitetraciclina 82 ppm e 8 - testemunha, foram aplicados quatro vezes, sendo avaliada a incidência da doença em frutos, 67 dias após plantio. In vitro, 300, 500 e 700 ppm de kasugamicina inibiram significativamente o crescimento do patógeno, diferindo dos demais tratamentos, mas não diferindo entre si (teste não paramétrico de Friedman, $\mathrm{P}=0,01$ ). Nos campos do $\mathrm{RN}$ e $\mathrm{CE}$, incidências médias da doença de 67,8 e 46,3\%, respectivamente, foram registradas inicialmente. Aos 67 dias após plantio, os tratamentos 4 e 6 no RN, bem como 5 e 7 no CE, reduziram significativamente a incidência da doença em frutos, com relação aos demais (teste $\mathrm{z}$ de duas proporções, $\mathrm{P}=0,05$ ).

Palavras-chave adicionais: Acidovorax avenae subsp. citrulli, controle químico, Cucumis melo, antibiótico.

\begin{abstract}
Kasugamycin and copper oxichloride effect on bacterial blotch of melon

Bacterial blotch caused by Acidovorax avenae subsp. citrulli is the most important bacterial disease of melon (Cucumis melo) in Northeastern Brazil. In an attempt to find alternatives for controlling this disease, several dosages of kasugamycin $(100,200,300,500$ and $700 \mathrm{ppm})$, copper oxichloride $(500 \mathrm{ppm})$ and a mixture of the two products $(200+500 \mathrm{ppm})$ were evaluated for pathogen inhibition in vitro. Two field experiments were performed in Rio Grande do Norte (RN) and Ceará (CE) where disease incidence was initially determined. The treatments: 1 to 4 - kasugamycin 40, 50, 60 and 70 ppm; 5 kasugamycin + copper oxichloride $40+1250$ ppm; 6 - copper oxichloride 1250 ppm; 7 - oxitetracyclin salt 82 ppm and 8 control were applied four times and evaluation was carried out 67 days after planting by recording disease incidence on fruits. In vitro 300, 500 and $700 \mathrm{ppm}$ of kasugamycin significantly inhibited pathogen growth, differing from the other treatments but not among them (Friedman non parametric test, $\mathrm{P}=0.01$ ). In field experiments in $\mathrm{RN}$ and $\mathrm{CE}$, disease incidence was recorded initially at 67.8 and $46.3 \%$, respectively. Sixty-seven days after planting, treatments 4 and 6 in RN, as well as 5 and 7 in CE, significantly reduced disease incidence on fruits (two-tailed $\mathrm{z}$ test, $\mathrm{P}=0.05$ ).
\end{abstract}

Additional keywords: Acidovorax avenae subsp. citrulli, chemical control, Cucumis melo, antibiotics.

A mancha-aquosa do meloeiro (Cucumis melo L.) causada por Acidovorax avenae subsp. citrulli (Schaad et al.) Willems et al. (Willems et al., 1992) é atualmente o principal problema fitossanitário que afeta o cultivo desta olerícola, na estação das chuvas nos estados do Ceará e Rio Grande do Norte. No Rio Grande do Norte, a doença tem sido observada com prevalência de $100 \%$ e incidência de até $47,29 \%$ (Silva, 2002), causando perdas de 40 a $50 \%$, que podem atingir até $100 \%$ em algumas áreas produtoras no período chuvoso (Sales Júnior \& Menezes, 2001). A mancha-

* Bolsista do CNPq

** Bolsista do PIBIC/CNPq aquosa ocorre principalmente no melão amarelo, que é o mais cultivado, mas os tipos Cantaloupe, Charantais, Gália, Orange Flesh, e, principalmente, Pele de Sapo também são susceptíveis à bactéria (Silva, 2002).

Dentre os produtos cúpricos que possuem ação bactericida, o oxicloreto de cobre é um dos mais eficientes, sendo recomendado para o controle de várias fitobacterioses (Kimati et al., 1997). Por outro lado, a kasugamicina é um antibiótico recomendado para o controle de canela-preta em batata, cancro bacteriano em tomateiro e podridão-mole em cenoura (Lopes \& Quezado-Soares, 1997).

Tendo em vista a crescente importância da mancha- 
aquosa do meloeiro e que ainda não foi descrita nenhuma forma de controle eficiente no Brasil, o presente trabalho objetivou estudar a sensibilidade de $A$. avenae subsp. citrulli à kasugamicina e oxicloreto de cobre in vitro e a eficiência destes produtos no controle da mancha-aquosa em campos de produção de melão com incidência natural da doença.

\section{Sensibilidade in vitro de $A$. avenae subsp. citrulli à kasugamicina e oxicloreto de cobre}

$\mathrm{O}$ ensaio in vitro foi realizado pelo método de antibiograma (Mariano et al., 2000), no Laboratório de Fitobacteriologia da Universidade Federal Rural de Pernambuco, Recife-PE.

Foram utilizados dez isolados de $A$. avenae subsp. citrulli: $1.12 ; 1.36 ; 1.37 ; 1.39 ; 1.43 ; 1.50 ; 1.71$ e 1.72 (obtidos de melão tipo Amarelo), MP1 [melão pepino (C. melo var. cantalupensis Naud.)] e 5.16 (melão tipo Pele de Sapo), todos obtidos de frutos infetados provenientes do Rio Grande do Norte.

Foram testadas diferentes concentrações de kasugamicina $(100,200,300,500$ e 700 ppm), oxicloreto de cobre $(500 \mathrm{ppm})$ e da mistura kasugamicina + oxicloreto de cobre $(200 \mathrm{ppm}+500 \mathrm{ppm})$. A avaliação foi realizada após $24 \mathrm{~h}$ medindo-se os halos de inibição dos isolados. O delineamento experimental foi inteiramente casualizado, em arranjo fatorial $10 \mathrm{x} 8$, correspondendo a dez isolados e oito produtos/ concentrações, incluindo a testemunha. Cada tratamento teve cinco repetições. Os dados obtidos foram analisados mediante o teste não-paramétrico de Friedman $(\mathrm{P}=0,01)$.

\section{Eficiência do tratamento químico no controle da mancha- aquosa do meloeiro em campos de produção em Mossoró, RN e Icapuí, CE \\ Em Mossoró, o plantio da cultivar AF-646 foi realizado} em 12 de janeiro de 2002 e em Icapuí, o plantio da cultivar Frevo foi feito em 2 de abril de 2002, ambos do tipo Amarelo e com densidade de 18.000 plantas.ha $^{-1}$. Nos dois ensaios, antes da aplicação dos produtos, foi avaliada a incidência da doença nas plantas. Os produtos utilizados em cada tratamento e suas diferentes concentrações foram: 1 a 4 - kasugamicina 40, 50, 60 e 70 ppm, 5 - oxicloreto de cobre 1250 ppm, 6 kasugamicina + oxicloreto de cobre $(40+1250 \mathrm{ppm})$ e 7 - sal de oxitetraciclina $82 \mathrm{ppm}$. A testemunha foi tratada com água. As aplicações foram iniciadas aos 23 dias após plantio, antes do florescimento e realizadas em um total de quatro, com intervalo de sete dias. As pulverizações foram feitas utilizando-se pulverizador costal JACTO acoplado com um bico cônico DJ2 dirigindo-se o jato diretamente às folhas e frutos. O volume de calda utilizado no ensaio variou de 300 a $800 \mathrm{l} \cdot \mathrm{ha}^{-1}$ indo de acordo com o desenvolvimento fenológico da cultura. A avaliação foi realizada observando-se a incidência da doença em frutos 67 dias após o plantio. $\mathrm{O}$ delineamento experimental foi inteiramente casualizado, com oito tratamentos e quatro repetições. Cada parcela experimental foi representada por quatro linhas com $5 \mathrm{~m}$ e a área útil do ensaio correspondeu às duas linhas centrais, totalizando 10 m. Em Mossoró, durante a realização do ensaio, houve precipitação de $315 \mathrm{~mm}$, distribuídos nos meses de janeiro (117,5 $\mathrm{mm})$, fevereiro $(29 \mathrm{~mm})$ e março $(168,5 \mathrm{~mm})$. Em Icapuí, ocorreu precipitação de $364 \mathrm{~mm}$, distribuídos nos meses de março $(208 \mathrm{~mm})$, abril $(151 \mathrm{~mm})$ e maio $(5 \mathrm{~mm})$. Os dados obtidos foram analisados mediante $\mathrm{o}$ teste $\mathrm{z}$ de duas proporções $(\mathrm{P}=0,05)$ (Triola, 1998).

Os isolados de A. avenae subsp. citrulli apresentaram diferenças significativas quanto à sensibilidade aos produtos testados. Os isolados 1.71 e 1.36 foram resistentes a 700 ppm de kasugamicina. Entre os produtos e concentrações testados, somente kasugamicina a 300,500 e $700 \mathrm{ppm}$ inibiu o crescimento da maioria dos isolados.

O tratamento com 700 ppm de kasugamicina não diferiu daqueles com 500 e 300 ppm, mas diferiu dos demais, indicando a sensibilidade de $A$. avenae subsp. citrulli à concentração mais alta desse antibiótico (Tabela 1).

Kasugamicina é um antibiótico recomendado para controle de doenças fúngicas, especialmente a brusone do arroz (Kimati et al., 1997) e bacterianas causadas por espécies dos gêneros Erwinia e Clavibacter (Lopes \& Quesado-Soares, 1997), mas não existem recomendações deste ou de outros antibióticos para controle da mancha-aquosa ou outras doenças causadas por Acidovorax spp. Uma vez que A. avenae subsp. citrulli mostrou-se sensível in vitro à kasugamicina, este antibiótico foi testado em campo.

Em Mossoró-RN, a incidência da mancha-aquosa em plantas de melão amarelo, antes das pulverizações, variou de 65,0 a $70,6 \%$, com média de $67,8 \%$. Esta média foi bem mais elevada que as já relatadas para esta doença, no Rio Grande do Norte, onde levantamento de campo no ano de 2001 detectou incidência variando entre 4,30 e 47,29\% com média de 21,85\%, incluindo melões tipo Amarelo e Pele de Sapo (Silva, 2002). No entanto, quando a mancha-aquosa foi detectada inicialmente, no RN, a incidência observada foi apenas de 5\% em frutos de melão (Assis et al., 1999).

Aos 67 dias após o plantio, as menores incidências em frutos foram verificadas nos tratamentos oxicloreto de cobre 1250 ppm e kasugamicina 70 ppm (Tabela 2). Estes valores foram significativamente menores que os obtidos nos tratamentos Kasugamicina 40, 50, 60 ppm e testemunha (Tabela 2). A oxitetraciclina $82 \mathrm{ppm}$ também diferiu da testemunha, apresentando uma menor percentagem de frutos infetados. Foram observadas diferenças entre as percentagens em apenas 32,14\% dos contrastes (Tabela 2).

Mesmo com uma elevada incidência de manchaaquosa no início do experimento, as perdas de frutos foram relativamente baixas. Isto pode ser explicado pela baixa precipitação ocorrida no período da floração e do desenvolvimento dos frutos, o que pode ter reduzido a disseminação da bactéria e a intensidade da doença. Sabe-se que a disseminação desse patógeno das folhas para flores e frutos jovens ocorre principalmente, por meio de respingos de chuvas e que, a alta umidade e temperaturas elevadas, favorecem o progresso da doença (Mariano et al., 2001).

Em Icapuí-CE, a incidência da mancha-aquosa em 
TABELA 1 - Efeito de bactericidas sobre o crescimento in vitro de Acidovorax avenae subsp. citrulli

\begin{tabular}{|c|c|}
\hline Tratamento (ppm) & Halo de inibição (mm) \\
\hline testemunha & $3,5 \mathbf{b}^{1}$ \\
\hline kasugamicina 100 & $3,5 \mathrm{~b}$ \\
\hline kasugamicina 200 & $3,5 \mathrm{~b}$ \\
\hline kasugamicina 300 & $4,7 \mathrm{ab}$ \\
\hline kasugamicina 500 & 6,7ab \\
\hline kasugamicina 700 & $7,1 \mathbf{a}$ \\
\hline oxicloreto de cobre 500 & $3,5 b$ \\
\hline $\begin{array}{l}\text { kasugamicina }+ \text { oxicloreto de cobre } 200+500 \\
\qquad \chi^{2}=52,0^{*}\end{array}$ & $3,5 \mathbf{b}$ \\
\hline
\end{tabular}

*Significativo a $1 \%$ de probabilidade

${ }^{1}$ Médias de cinco repetições. Médias seguidas pela mesma letra não diferem entre si pelo Teste de comparações múltiplas de Friedman. plantas, antes das pulverizações, variou de 40,1 a 51,2\%. Esta média é também superior àquela detectada $(21,85 \%) \mathrm{em}$ levantamento realizado em 2001 nos municípios de Mossoró e Baraúna (Silva, 2002).

Aos 67 dias após o plantio, os tratamentos sal de oxitetraciclina 82 ppm e kasugamicina + oxicloreto de cobre (40 +1250 ppm) reduziram 36,4\% significativamente a incidência da doença em relação aos tratamentos kasugamicina 50 60 ppm e testemunha (Tabela 3). Também foram constatadas diferenças entre os tratamentos sal de oxitetraciclina $82 \mathrm{ppm}$ e kasugamicina $70 \mathrm{ppm}$. Foram observadas diferenças entre as percentagens em apenas $25 \%$ dos contrastes (Tabela 3 ).

A incidência da doença nos frutos foi mais elevada no ensaio de Icapuí-CE do que no ensaio de Mossoró-RN. A precipitação de $151 \mathrm{~mm}$ que ocorreu no período de floração e

TABELA 2 - Valores de Z obtidos pelo teste de duas proporções entre tratamentos em Mossoró-RN e percentagem média da incidência da mancha-aquosa em frutos de melão (Cucumis melo) 67 dias após o tratamento com bactericidas. Mossoró-RN, 2003

\begin{tabular}{|c|c|c|c|c|c|c|c|c|}
\hline Bactericida $^{1}$ (ppm) & ks 40 & ks 50 & ks 60 & ks 70 & ks $40+\operatorname{oxcl} 1250$ & oxcl 1250 & oxtt 82 & test \\
\hline ks 40 & - & $0,2224^{\mathrm{ns}}$ & $0,1670^{\mathrm{ns}}$ & $-1,7782^{*}$ & $-1,1049^{\mathrm{ns}}$ & $-1,7797^{*}$ & $-1,3102^{\mathrm{ns}}$ & $0,499^{\text {ns }}$ \\
\hline ks 50 & - & - & $0,0555^{\text {ns }}$ & $-1,9882^{*}$ & $-1,3214^{\mathrm{ns}}$ & $-1,9860^{*}$ & $-1,5240^{\mathrm{ns}}$ & $0,278^{\text {ns }}$ \\
\hline ks 60 & - & - & - & $-1,9411^{*}$ & $-1,2696^{\mathrm{ns}}$ & $-1,9397^{*}$ & $-1.4736^{\mathrm{ns}}$ & $0,333^{\text {ns }}$ \\
\hline ks 70 & - & - & - & - & $0,6755^{\mathrm{ns}}$ & $-0,0182^{\mathrm{ns}}$ & $0.4666^{\mathrm{ns}}$ & $2,264^{*}$ \\
\hline ks $40+$ oxcl 1250 & - & - & - & - & - & $-0,6908^{\mathrm{ns}}$ & $-0.2088^{\mathrm{ns}}$ & $1,597^{\mathrm{ns}}$ \\
\hline $\operatorname{oxcl} 1250$ & - & - & - & - & - & - & $0.4834^{\mathrm{ns}}$ & $2,257^{*}$ \\
\hline oxtt 82 & - & - & - & - & - & - & - & $1,798^{*}$ \\
\hline testemunha & - & - & - & - & - & - & - & - \\
\hline Médias $^{2}$ & Ks40 & Ks50 & Ks60 & Ks70 & Ks40+oxcl 1250 & oxcl 1250 & Oxtt 82 & test \\
\hline Mossoro & 8,0 & 8,6 & 8,4 & 3,9 & 5,3 & 3,8 & 4,8 & 9,4 \\
\hline
\end{tabular}

${ }^{1} \mathrm{ks}=$ kasugamicina; oxcl = oxicloreto de cobre; oxtt = sal de oxitetraciclina; test $=$ testemunha

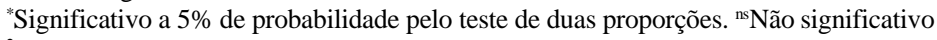

${ }^{2}$ Média de quatro repetições

TABELA 3 - Valores de Z obtidos pelo teste de duas proporções entre tratamentos em Icapuí-CE e percentagem média da incidência da mancha-aquosa em frutos de melão (Cucumis melo) 67 dias após o tratamento com bactericidas. Mossoró-RN, 2003

\begin{tabular}{|c|c|c|c|c|c|c|c|c|}
\hline Bactericida' (ppm) & ks 40 & ks 50 & ks 60 & ks 70 & ks $40+$ oxcl 1250 & oxcl 1250 & oxtt 82 & test \\
\hline ks 40 & - & $0,4745^{\mathrm{ns}}$ & $0,3994^{\text {ns }}$ & $0,1249^{\mathrm{ns}}$ & $-1,4702^{\text {ns }}$ & $-0,3103^{\mathrm{ns}}$ & $-1,5934^{\text {ns }}$ & $0,8037^{\text {ns }}$ \\
\hline ks 50 & - & - & $-0,0751^{\mathrm{ns}}$ & $-0,3496^{\mathrm{ns}}$ & $-1,9430^{*}$ & $-0,7846^{\mathrm{ns}}$ & $-2,0660^{*}$ & $0,3294^{\mathrm{ns}}$ \\
\hline $\mathrm{ks} 60$ & - & - & - & $-0,2745^{\mathrm{ns}}$ & $-1,8681^{*}$ & $-0,7095^{\mathrm{ns}}$ & $-1,9912^{*}$ & $0,4045^{\mathrm{ns}}$ \\
\hline ks 70 & - & - & - & - & $-1,5951^{\mathrm{ns}}$ & $-0,4352^{\mathrm{ns}}$ & $-1,7183^{*}$ & $0,6789^{\mathrm{ns}}$ \\
\hline ks $40+$ oxcl 1250 & - & - & - & - & - & $1,1610^{\mathrm{ns}}$ & $-0,1234^{\mathrm{ns}}$ & $2,2705^{*}$ \\
\hline $\operatorname{oxcl} 1250$ & - & - & - & - & - & - & $-1,2844^{\mathrm{ns}}$ & $1,1136^{\mathrm{ns}}$ \\
\hline oxtt 82 & - & - & - & - & - & - & - & $2,3933^{*}$ \\
\hline testemunha & - & - & - & - & - & - & - & - \\
\hline Médias $^{2}$ & Ks40 & Ks50 & Ks60 & Ks70 & Ks40+oxcl 1250 & oxcl 1250 & Oxtt 82 & test \\
\hline Icapui & 43,5 & 45,9 & 45,5 & 44,2 & 36,4 & 42,0 & 35,8 & 47,5 \\
\hline
\end{tabular}

${ }^{1} \mathrm{ks}=$ kasugamicina; oxcl = oxicloreto de cobre; oxtt = sal de oxitetraciclina; test = testemunha

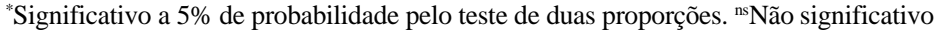

${ }^{2}$ Média de quatro repetições 
desenvolvimento dos frutos, além de lavar o produto aplicado, foi favorável à disseminação da $A$. avenae subsp. citrulli. Portanto, uma alta incidência da mancha-aquosa em folhas pode não resultar em alta incidência nos frutos, quando a floração e desenvolvimento dos frutos até os 50 dias, consideradas épocas críticas para a infecção, não coincidem com alta precipitação. Isto reforça a recomendação do plantio em épocas de estiagem, como uma das medidas de manejo da doença.

A eficiência quanto à redução de incidência da doença obtida pela kasugamicina $70 \mathrm{ppm}$ e pelo oxicloreto de cobre 1250 ppm foram observadas separadamente em Mossoró, em condições desfavoráveis à doença, não havendo sinergismo entre os dois tratamentos. Já em Icapuí, sob condições favoráveis à doença, foi observada a eficiência para a mistura kasugamicina + oxicloreto de cobre $(40+1250 \mathrm{ppm})$ e para o sal de oxitetraciclina $82 \mathrm{ppm}$. De acordo com Luisetti et al. (1989), kasugamicina a $500 \mathrm{ppm}$ foi muito eficiente na redução de populações epifíticas de patovares de Pseudomonas syringae van Hall em kiwi (Actinidia chinensis Planch.), videira (Vitis spp.) e pessegueiro [Prunus persicae (L.) Batsch]. A aplicação de 500 ppm, uma ou duas vezes, exerceu significativo controle de Xylophilus ampelinus (Panagopoulos) Willems et al. em videira. Portanto, o controle obtido neste trabalho pelo uso da kasugamicina na dosagem de 70 ppm, em condições desfavoráveis à doença, está em concordância com os resultados encontrados na literatura.

Sendo assim, segundo os dados obtidos neste trabalho, consideramos baseado no teste in vitro e nos dois ensaios de campo, que o ativo kasugamicina apresenta-se como uma excelente alternativa para o controle de $A$. avenae subsp. citrulli. Principalmente quando a mesma for alternada com aplicações de oxicloreto de cobre, ou de sal de oxitetraciclina.

\section{REFERÊNCIAS BIBLIOGRÁFICAS}

ASSIS, S.M.P., MARIANO, L.R.M., SILVA-HANLIN, D.M.W. \& DUARTE, V. Mancha-aquosa do melão causada por Acidovorax avenae subsp. citrulli, no estado do Rio Grande do Norte. Fitopatologia Brasileira 24:191. 1999. (Resumo)

KIMATI, H., GIMENES-FERNANDES, N., SOAVE, J., KUROZAWA, C., BRIGNANI NETO, F. \& BETTIOL, W. Guia de fungicidas agrícolas. Volume I - Recomendações por cultura. $2^{\text {a }}$. ed. Jaboticabal. Grupo Paulista de Fitopatologia. 1997.

LOPES, C.A. \& QUEZADO-SOARES, A.M. Doenças bacterianas das hortaliças - Diagnose e Controle. Brasília. Embrapa-CNPH. 1997.

LUISETTI, J., GAIGNARD, J.L. \& RIDE, M. Ability of kasumin to control some phytopathogenic bacteria. Proceedings $7^{\text {th }}$ International Conference Plant Pathology, Budapest, Hungria. 1989. pp.213-218.

MARIANO, R.L.R., ASSIS, S.M.P., SILVEIRA, E.B. \& GOMES, A.M.A. Substâncias químicas para controle de bactérias fitopatogênicas. In: Mariano, R.L.R. (Coord.) Manual de práticas em fitobacteriologia. Recife. Editora Universitária. 2000. pp.111113.

MARIANO, R.L.R., SILVEIRA, E.B; ASSIS, S.M.P., GOMES, A.M.A., OLIVEIRA, I.S. \& PEIXOTO, A.R. Diagnose e manejo de fitobacterioses de importância no nordeste brasileiro. In: Michereff, S.J. \& Barros, R. (Orgs.) Desafios da proteção de plantas na agricultura sustentável. Recife. UFRPE. 2001. pp.141-169.

SALES JÚNIOR \& MENEZES, J.B. Mapeamento das doenças fúngicas, bacterianas e viróticas do cultivo do melão no Estado do RN. Mossoró. Escola Superior de Agricultura de Mossoró. Relatório técnico. 2001.

SILVA, E.I. Levantamento da incidência da mancha-aquosa do melão nos municípios de Mossoró e Baraúna (Rio Grande do Norte, Brasil) e determinação do tamanho da amostra para quantificação da doença. (Dissertação de Mestrado). Recife. Universidade Federal Rural de Pernambuco. 2002.

TRIOLA, M. F. Introdução à Estatística. $7^{\mathrm{a}}$ ed. Rio de Janeiro. Editora LTC. 1998.

WILlEMS, A., GOOR, M., THIELEMANS, S., GILLIS, M., KERSTERS, K. \& DE LEY, J. Transfer of several phytopathogenic Pseudomonas species to Acidovorax as Acidovorax avenae subsp. avenae subsp. nov., comb. nov., Acidovorax avenae subsp. citrulli, Acidovorax avenae subsp. cattleyae, and Acidovorax konjaci. International Journal Systematic of Bacteriology 42:107-119.1992. 